\title{
TIPOLOGI SISTEM BUDIDAYA PERTANIAN DAN KEBERLANJUTAN KETERSEDIAAN PANGAN PADA MASYARAKAT ADAT KASEPUHAN CIPTAGELAR SUKABUMI
}

\author{
Ikmaludin $^{1 *}$, Cecep Kusmana ${ }^{2}$, Suwaib Amirudin ${ }^{3}$ \\ ${ }^{1}$ Program Ilmu Pengelolaan Sumberdaya Alam dan Lingkungan, Pascasarjana Institut Pertanian \\ Bogor (IPB), ${ }^{2}$ Departemen Silvikultur, Fakultas Kehutanan, Institut Pertanian Bogor (IPB) \\ ${ }^{3}$ Fakultas Ilmu Sosial dan Ilmu Politik, Universitas Sultan Ageng Tirtayasa \\ *Email: ikmaludin1189@gmail.com
}

\section{RINGKASAN}

Kasepuhan Ciptagelar adalah permukiman masyarakat tradisional di Kabupaten Sukabumi, Jawa Barat yang masih mempertahankan warisan budaya tradisional dan sistem pertanian. Kasepuhan dianggap memiliki sistem ketahanan pangan yang baik sehingga menarik untuk dipelajari lebih dalam. Tujuan dari penelitian ini adalah untuk menggambarkan kearifan lokal dalam sistem pertanian masyarakat Kasepuhan Ciptagelar, menganalisis aspek sosial ekonomi dan ketersediaan makanan rumah tangga dari komunitas Kasepuhan Ciptagelar dan menganalisis daya dukung masyarakat petani Kasepuhan Ciptagelar. Metode penelitian dilakukan dengan cara wawancara, diskusi dan observasi lapangan pada 52 responden. Hasil penelitian menunjukkan bahwa kearifan lokal budidaya pertanian di Kasepuhan Ciptagelar tentang ketersediaan pangan dilihat dari kepatuhan terhadap tradisi leluhur atau melaksanakan ajaran tatali paranti karubun, budidaya pertanian yang dilakukan yaitu sawah dan huma. Berdasarkan pendapatan beras rata-rata rumah tangga petani responden, kisarannya adalah 0-250 ikatan, $31 \mathrm{kk}, 251-500$ ikatan, $16 \mathrm{kk}$ dan kisarannya adalah 501-750 bundel, 5 kk. Produksi gabah giling dari 52 responden mencapai 13.358 tandan atau pocong yang terdiri dari 12.660 tandan dan 698 tandan (1 kg setara dengan $4 \mathrm{~kg}$ ). Luas panen adalah 48.115, jumlah penduduk 186, kebutuhan fisik minimum 124,80 dan ratarata produksi lahan per hektar adalah 694,07. Daya dukung lahan pertanian adalah 1,44. Menunjukkan bahwa masyarakat Kasepuhan Ciptagelar mampu swasembada pangan.

Kata Kunci: Daya Dukung Lahan, Kasepuhan Ciptagelar, Kearifan Lokal, Ketersediaan Pangan.

\section{PERNYATAAN KUNCI}

- Nilai daya dukung lahan diperoleh besarnya daya dukung lahan Kasepuhan
Ciptagelar yaitu sebesar 1,44. Nilai tersebut menunjukkan bahwa

Masyarakat Kasepuhan Ciptagelar 
sudah mampu melaksanakan swasembada pangan dan persediaan beras untuk dikonsumsi oleh masyarakat Kasepuhan Ciptagelar jauh melebihi kebutuhan.

- Salah satu yang melambangkan bahwa masyarakat di Kasepuhan Ciptagelar memiliki ketahanan pangan yang kuat adalah dengan adanya Leuit si jimat (Lumbung padi) Leuit si Jimat merupakan Leuit besar dimiliki pemimpin adat secara turun temurun

- Kearifan lokal budidaya pertanian di Kasepuhan Ciptagelar terhadap ketersediaan pangan terlihat dari pelaksanaan ajaran tatali paranti karuhun.

- Produksi pangan seperti tanaman padi, jagung, ubi kayu, ubi jalar, kacangkacangan dan sayuran yang dibudidayakan di lahan dilakukan dalam rangka untuk menjamin keberlanjutan ketersediaan pangan

\section{REKOMENDASI KEBIJAKAN}

Kearifan lokal sistem budidaya pertanian masyarakat Kasepuhan Ciptagelar sebaiknya dipertimbangkan dalam mengembangkan konsep pembangunan pertanian berkelanjutan.

\section{PENDAHULUAN}

Sektor pertanian merupakan salah satu sektor terpenting dalam pembangunan di
Indonesia dan sebagai penghasil komoditi untuk pemenuhan kebutuhan pangan. Pangan adalah segala sesuatu yang berasal dari sumber hayati produk pertanian, perkebunan, kehutanan, perikanan dan peternakan, baik yang diolah maupun tidak diolah yang diperuntukan sebagai makanan atau minuman bagi konsumsi manusia, termasuk bahan tambahan pangan, bahan baku pangan, dan bahan lainnya yang digunakan dalam proses penyiapan, pengolahan, dan atau pembuatan makanan atau minuman (UU No 18 Tahun 2012). Menurut Saleh (1999) bahwa penyediaan pangan untuk memenuhi kebutuhan seluruh penduduk suatu Negara/Wilayah sebenarnya tidak selalu mengandalkan kemampuan negara untuk memproduksi pangan yang diperlukan.

Kasepuhan Ciptagelar, merupakan salah satu masyarakat adat yang tinggal di kawasan Taman Nasional Gunung Halimun Salak (TNGHS), Jawa Barat. Tatali paranti karuhun menjadi dasar budaya masyarakat kasepuhan untuk tetap mempertahankan kearifan lokal sebagai implementasi filosofi hidupnya dalam bentuk religi, pandangan hidup, mata pencaharian dan aktivitas sosial budaya yang berjalan dari generasi satu ke generasi selanjutnya. Penanaman padi di Kasepuhan Ciptagelar dilakukan satu tahun sekali dan secara alami, dengan sedikit sekali atau bahkan tidak menggunakan pestisida, 
serta tidak menggunakan peralatan pertanian modern, seperti traktor. Dengan menanam padi setahun sekali, diharapkan dapat menghentikan siklus hama wereng yang biasanya jatuh pada bulan dan musim yang sudah diperhitungkan (Khomsan 2014). Hal ini diduga mempengaruhi karakteristik sosiobudaya pangan dan gizi yang didasari kepada nilai-nilai tradisi yang hingga hari ini masih dipegang oleh masyarakat Kasepuhan (Kusnaka 1992).

Sistem pertanian di Kasepuhan Ciptagelar ini selalu menggunakan bibit lokal yang telah digunakan secara turun temurun. Alasan penggunaan bibit lokal yaitu : 1) upacara adat mengharuskan menggunakan padi lokal, 2) padi jenis unggul yang dianjurkan pemerintah tidak dapat tumbuh dengan baik di daerah lembab dan terlalu dingin, 3) padi jenis lokal berbatang panjang sehingga memudahkan dietem, mudah pengeringan dan penyimpanannya, tahan sampai waktu lebih dari 5 tahun dan tidak rontok, dan 4) melestarikan adat leluhur, karena sampai sekarang ada sekitar 43 jenis pare rurukan (padi pokok) dan 168 jenis padi hasil silang dari pare rurukan (Tim Wacana Nusantara 2012).

Ketahanan pangan merupakan salah satu hal yang sangat dijunjung tinggi oleh masyarakat Kasepuhan Ciptagelar. Untuk mencukupi kebutuhan pangan dan gizi masyarakat kasepuhan tidak hanya menanam padi tetapi juga berbagai jenis sayuran dan hortikultura lainnya. Pangan sebagai Hak Asasi Manusia menyaratkan bahwa setiap orang harus memiliki akses terhadap pangan yang aman, begizi dan layak secara budaya, cukup baik kuantitas maupun kualitasnya demi menjamin kehidupan yang sehat sebagai manusia yang bermartabat. Setiap bangsa hendaknya mendeklarasikan bahwa akses terhadap pangan merupakan hak konstitsional dan menjamin pengembangan sektor primer untuk menjamin realisasi secara nyata dari hak mendasar ini (right to food) (Bernatain 2014).

Berdasarkan hasil observasi ditemukan bahwa sistem sosial ekonomi dan budaya yang dimiliki masyarakat Kasepuhan Ciptagelar memiliki beberapa persamaan dengan sosial ekonomi dan budaya pada masyarakat adat lainnya, akan tetapi sistem kearifan lokal dalam pengolahan lahan pertanian yang dimiliki oleh masyarakat Kasepuhan Ciptagelar sebagai petani serta kebiasaan yang terbentuk pada masyarakat tersebut dinilai mampu mencukupi kebutuhan pangan sehari-hari masyarakat setempat. Berdasarkan fenomena itu, mendeskripsikan kearifan lokal dalam sistem pertanian masyarakat Kasepuhan Ciptagelar, menganalisis aspek sosial ekonomi dan ketersediaan pangan rumah tangga masyarakat Kasepuhan Ciptagelar dan 
menganalisis daya dukung lahan pertanian masyarakat Kasepuhan Ciptagelar.

\section{SITUASI TERKINI TERHADAP ISU YANG DIBAHAS}

Kasepuhan Ciptagelar adalah salah satu kampung adat yang masuk dalam kesatuan adat banten kidul. Kasepuhan Adat Ciptagelar masih memegang kuat adat dan tradisi yang diturunkan. Kasepuhan ini dipimpin oleh seorang abah yang diangkat berdasarkan keturunan. Saat ini, Kesepuhan Ciptagelar dipimpin oleh abah Ugi Rakasiwi. Masyarakat Kasepuhan Ciptagelar adalah masyarakat agraris yang mendiami kawasan Taman Nasional Gunung Halimun yang berlokasi di Desa Sirna Resmi Kecamatan Cisolok Kabupaten Sukabumi. Sistem pertanian Kasepuhan Ciptagelar yang masih melaksanakan pertanian subsisten mampu mencukupi kebutuhan pangan masyarakanya.

\section{METODOLOGI}

Penelitian dilakukan di masyarakat adat Kasepuhan Ciptagelar, Desa Sinaresmi, Kecamatan Cisolok, Kabupaten Sukabumi (Gambar 1). Penelitian dilaksanakan pada bulan Oktober 2017 sampai dengan bulan Februari 2018. Secara geografis desa ini terletak antara $106^{\circ} 27^{\prime}-106^{\circ} 33^{\prime}$ BT dan $6^{\circ}$ 52'-6 $6^{\circ}$ 4' LS. Batas-batas Desa Sinaresmi antara lain sebelah utara berbatasan dengan Desa Sirna Galih, sebelah selatan dan barat berbatasan dengan Desa Cicadas dan sebelah timur berbatasan dengan Desa Cihamerang.

Alat dan bahan yang digunakan dalam penelitian ini berupa perangkat komputer yang dilengkapi dengan Microsoft Office, Microsoft Excel, peta lokasi penelitian, kamera, recorder, pedoman wawancara, kompas, dan alat tulis menulis. Data yang digunakan berupa data primer dan data sekunder. Data primer adalah data yang dihasilkan dari hasil kuesioner, wawancara

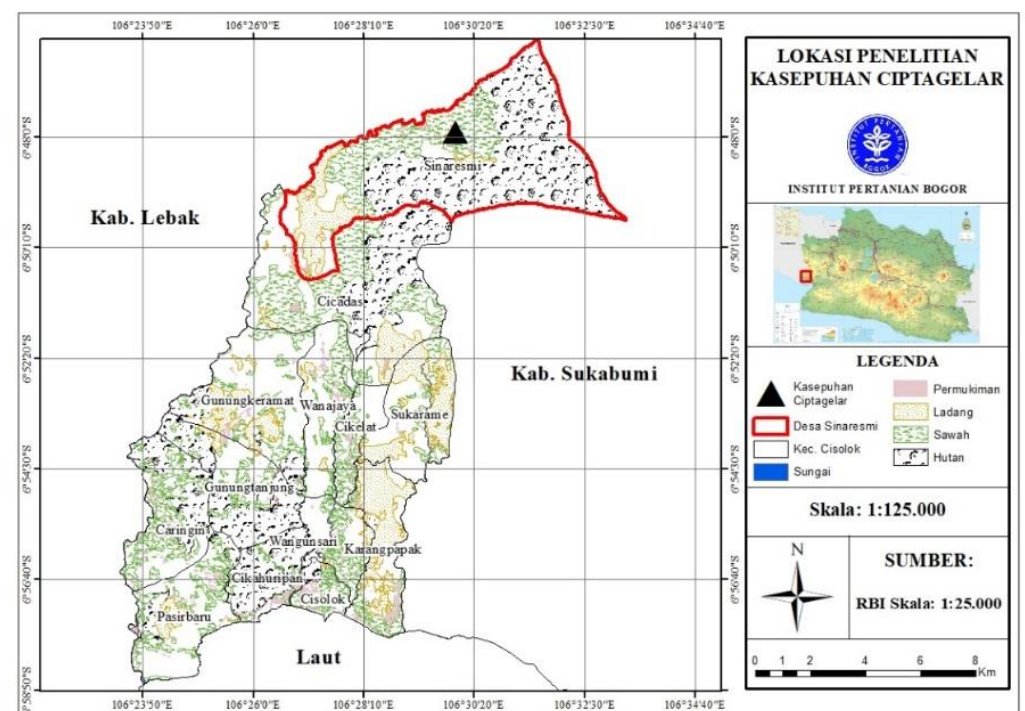

Gambar 1 Lokasi Kasepuhan Ciptagelar 
dengan beberapa kepala keluarga contoh sebagai responden, dan survey langsung aspek lain di lokasi penelitian. Data sekunder adalah data yang dikumpulkan dari kepustakaan, informasi dari lembaga tertentu, baik pemerintah maupun non pemerintah, peta, laporan-laporan dan publikasi lain yang relevan.

Populasi sasaran dalam penelitian ini adalah semua kepala keluarga (KK) di Kasepuhan Ciptagelar yang mempunyai lahan garapan pertanian. Berdasarkan survey awal yang dilakukan, jumlah populasi di Kasepuhan Ciptagelar adalah sebanyak 120 KK. Ukuran minimal contoh (rumah tangga) dalam penelitian ini ditentukan dengan menggunakan rumus Slovin dalam Umar (2001), sebagai berikut:

$$
n=\frac{N}{1+N e^{2}}
$$

Dimana:

$$
\begin{array}{ll}
\mathrm{n} & =\text { ukuran sampel yang akan dipilih } \\
\mathrm{N} & =\text { ukuran populasi }(120 \mathrm{KK}) \\
\mathrm{e} & =\text { persen kelonggaran ketidaktelitian }
\end{array}
$$
karena kesalahan pengambilan sampel yang masih dapat ditolerir, dalam hal ini $10 \%$.

Berdasarkan asumsi tersebut maka jumlah minimal contoh adalah:

$$
n=\frac{120 K K}{1+\left(120 \times 0.1 x^{2}\right)}
$$

$$
n=\frac{120}{2.2}=52 K K
$$

Berdasarkan hasil perhitungan, maka diperoleh jumlah sampel sebanyak $54 \mathrm{KK}$. Penarikan Contoh dilakukan dengan sistem pengacakan sederhana (Simple Random Sampling). Proses pengacakan dilakukan dengan menggunakan fungsi random pada program Microsoft Excel 2007.

Menganalisa daya dukung lahan pertanian dihitung untuk mendapatkan nilai daya dukung lahan pada setiap rumah tangga responden. Konsep daya dukung lahan pertanian yang dikembangkan Teori Odum, Christeiler, Ebenezer Howard dan Issard dalam Moniaga (2011), yaitu:

$$
\tau=\frac{L p / P d}{K F M / P r}
$$

Keterangan:

$\boldsymbol{\tau}=$ Daya dukung lahan pertanian

Lp = Luas lahan panen (ha)

Pd = Jumlah penduduk (jiwa)

KFM $=$ Kebutuhan Fisik Minimum (kg/kapita/tahun)

Pr $\quad=$ Produksi lahan rata-rata per hektar (kg/ha)

Bertolak dari teori tersebut, maka konsep daya dukung yang diajukan adalah konsep yang berangapan satu wilayah merupakan satu ekosistem. Kelestarian 
ekosistem tergantung kepada ketersediaan sumber daya yang cukup merata dan sirkulasinya berkelanjutan. Sumber daya yang dimaksud adalah sumber daya alam yang dapat diperbarui. Indikator yang digunakan adalah ketersediaan bahan makanan utama yaitu beras. Dengan asumsi apabila:

- $\sigma<1$ berarti wilayah tersebut tidak mampu melaksanakan swasembada pangan, atau dapat diartikan bahwa jumlah penduduknya telah melebihi jumlah penduduk optimal.

- $\sigma>1$ berarti wilayah tersebut mampu melaksanakan swasembada pangan, dalam arti jumlah penduduknya dibawah jumlah penduduk optimal.

- $\sigma=1$ berarti wilayah tersebut memiliki daya dukung lingkungan optimal. Jadi angka satu merupakan batas ambang daya dukung lingkungan.

\section{ANALISIS DAN ALTERNATIF SOLUSI ATAU PENANGANAN \\ Mendeskripsikan Kearifan Lokal dalam Sistem Pertanian}

Secara khusus yang membedakan sistem pertanian masyarakat Kasepuhan Ciptagelar dengan sistem pertanian masyarakat modern adalah sifat kealamiannya serta adanya aturan-aturan adat setempat dalam setiap prosesi pertanian antara lain; hanya memperbolehkan masyarakat setempat menanam padi sekali dalam setiap tahunnya, selalu menggunakan bibit lokal dan alat-alat pertanian tradisional, serta adanya upacaraupacara adat pada setiap rangkaian kegiatan bertani.

Di kalangan masyarakat Ciptagelar, pengelolaan sumberdaya hutan yang terintegrasi dengan pertanian secara tradisional (sawah dan huma) ditujukan untuk pemenuhan kebutuhan pangan seharisehari. Gambar 2. memperlihatkan contoh lahan padi huma dengan padi sawah di lokasi penelitian.

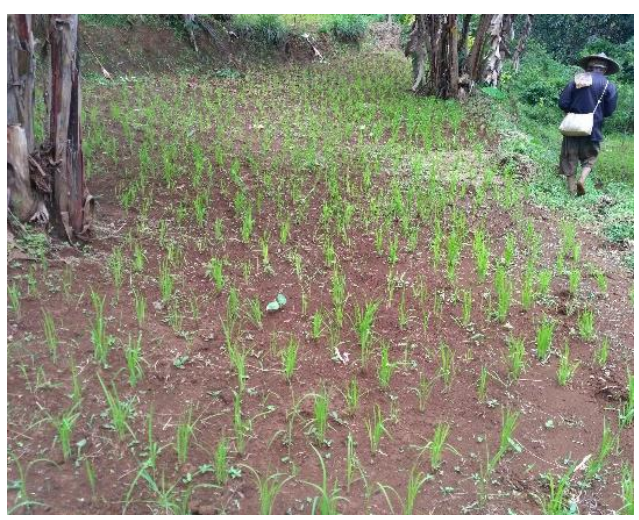

(a)

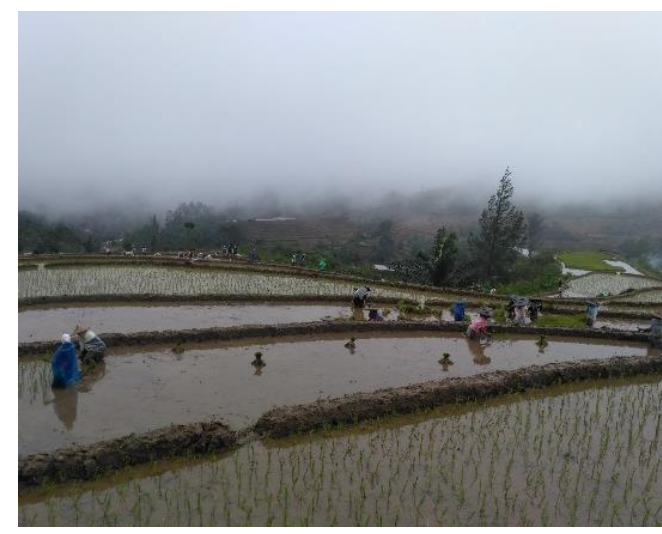

(b)

Gambar 2 Budidaya padi masyarakat kasepuhan Ciptagelar, (a) Padi Huma, dan (b) Padi Sawah 


\section{- Sawah}

Kegiatan bertani yang dominan adalah bersawah. Lokasi sawah terletak pada daerah lereng. Jenis sawah yang diusahakan adalah sawah tadah hujan yang sumber airnya berasal dari sungai-sungai dan mata air-mata air.

\section{- Huma}

Huma adalah sistem berladang yang berpindah-pindah. Huma biasa dilakukan untuk melakukan kegiatan bercocok tanam di ladang tanpa diairi seperti di sawah. Proses sistem pertanian masyarakat Kasepuhan Ciptagelar terdapat beberapa kegiatan, yaitu:

\section{a. Tata Waktu Budidaya}

Waktu menanam padi di Kasepuhan Ciptagelar dikenal dengan sistem perbintangan terdiri dari bintang Kerti dan Kidang yang dikenal pula sebagai "guru desa". Perubahan posisi kedua bintang ini menjadi pedoman dalam menentukan jenis kegiatan yang harus dilakukan, baik di sawah maupun huma.

\section{b. Zonasi}

Pengetahuan tentang pembagian zonasi lahan pada Masyarakat Kasepuhan Ciptagelar untuk digunakan sebagai kebutuhan pemukiman dan pertanian dibagai menjadi tiga zona, yaitu:

\section{- Leuweung Kolot/Geledegan/Awisan} adalah wilayah hutan yang sama sekali tidak dapat diganggu untuk kepentingan apapun, harus selalu dijaga.

- Leuweung Titipan adalah kawasan hutan yang diamanatkan kepada para incu putu untuk menjaga/tidak mengganggu kawasan hutan ini.

\section{- Leuweung Bukaan atau sampalan} adalah suatu kawasan hutan yang sekarang telah terbuka dan dapat digarap oleh masyarakat dan masih dikelola untuk sawah, huma dan kebun.

\section{c. Kesesuaian Lahan}

Penentuan kesesuaian lahan dilihat oleh abah ketika setelah mendapat wangsit, hal ini menjadi petunjuk sekaligus penanda lahan yang dipilih akan mendapatkan hasil pertanian yang baik.

d. Pemilihan Jenis

Jenis padi yang ditanam oleh warga Kasepuhan Ciptagelar adalah jenis padi lokal, terdapat 74 jenis padi lokal yang dimiliki dan pemilihan jenis padi yang ditanam tergantung dari selera petani. Jenis padi yang akan ditanam merupakan koleksi benih padi yang ada di Kasepuhan, namun varietas padi yang sering ditanam adalah varietas cere, varietas raja denok, dan varietas tampeuy.

e. Penyiapan Benih

Benih yang digunakan terlebih dahulu disimpan di dalam bangsal (tempat penyimpanan benih) agar kualitas benih tetap terjaga. Benih padi harus yang sudah tua. Benih yang dipilih adalah dari hasil 
panen sebelumnya, harus dipakai sebagai bagian dari tatali paranti karubun.

\section{f. Penanaman}

Padi huma ditanam langsung tanpa disemai sedangkan padi sawah proses tebar ( penyemaian) hingga waktu penananaman dibutuhkan waktu sekitar 70-73 hari penyemaian.

\section{g. Pemeliharaan}

Pemeliharaan padi tidak diperbolehkan menggunakan bahan-bahan kimia, seperti pestisida dan insektisida. Setelah umur 3-4 bulan padi sudah mulai berisi, kemudian dilakukan selamatan kembali dengan tujuan agar panen padi dapat menghasilkan padi yang maksimal.

\section{h. Pemanenan}

Panen dilakukan ketika hamparan tanaman padi terlihat menguning secara merata dan bulir padi telah padat. Umur tanaman padi yang siap panen sekitar 6-7 bulan (paling lama adalah 8-9 bulan, tapi jarang sekali). Padi huma bisa meraih panen sampai 40 ikat padi, sementara padi sawah mencapai 300 ikat dengan penggunaan bibit hanya 10 ikat (1 ikat setara dengan 4-5 kg).

i. Penyimpanan Hasil Panen

Pengelolaan dan pemanfaatan hasil panen padi di kalangan masyarakat Kasepuhan Ciptagelar dilakukan dalam suatu pranata ekonomi lokal yang dikenal sebagai sistem lenit atau lumbung padi.

j. Kapasitas, Jumlah dan Tata Letak Lenit
Menurut $\mathrm{Ki}$ Koyod baris olot yang bertugas mengurus pertanian, setiap keluarga petani di Kasepuhan Ciptagelar memiliki beberapa lenit kecil antara 1 hingga 5 lenit, dimana satu lenit dapat menampung 3001.000 pocong padi. Padi hasil panen yang tersimpan di lumbung tidak dipisahkan dari tangkainya, tetapi tetap tergantung dalam keadaan terikat menggunakan tali bambu (pocongan).

k. Lama Penyimpanan Hasil Panen

Padi yang tersimpan dalam leuit mampu bertahan hingga lima tahun bahkan bisa lebih tanpa mengalami kerusakan, leuit atau lumbung padi menjadi simbol ketahanan pangan masyarakat adat Kasepuhan Ciptagelar. Hal itu terjadi karena leuit berbentuk panggung, sehingga padi yang berada didalamnya tidak cepat basah/lembab karena adanya sirkulasi udara di bawah bangunan leuit, (kolong leuit) yang bisa menghangatkan ruangan melalui celahcelah.

\section{Menganalisis Aspek Sosial Ekonomi dan Ketersediaan Pangan Rumah Tangga}

\author{
a. Karakteristik Sosial Ekonomi Rumah \\ tangga
}

Karakteristik sosial ekonomi rumah tangga masyarakat Kasepuhan Ciptagelar yang diteliti meliputi rata-rata umur suami dan istri, besar keluarga, lama pendidikan dan pekerjaan. Karakteristik Sosial Ekonomi 
Rumah tangga masyarakat Kasepuhan Ciptagelar dapat dilihat pada Tabel 1.

Rata-rata umur baik umur suami maupun istri pada masyarakat Kasepuhan Ciptagelar termasuk ke dalam umur dewasa menengah yaitu antara 30-49 tahun (Depkes 2011). Menurut BPS (2012), rata-rata umur masyarakat Kasepuhan Ciptagelar tersebut tergolong umur produktif yaitu antara 16 - 62 tahun sehingga seharusnya merupakan kelompok usia efektif untuk bekerja serta menghasilkan pendapatan. Rata-rata besar keluarga setiap rumah tangga antara 2 - 4 orang.

Rata-rata lama pendidikan adalah $\leq 6$ tahun atau tidak tamat sekolah dasar.
Berdasarkan hasil observasi langsung untuk sekolah menengah pertama (SMP) dan sekolah menengah atas (SMA) baru berdiri di wilayah Kasepuhan Ciptagelar. Besaran keluarga kisaran 3-4 berjumlah $37 \mathrm{kk}$ $(71,15 \%)$ dari $52 \mathrm{kk}$ responden dan kisaran $0-2$ berjumlah $7 \mathrm{kk}(13,46 \%)$. Sedangkan yang memilik besaran kisaran $5-6$ berjumlah $8 \mathrm{kk}(15,38 \%)$. Nilai pendapatan padi per tahun masyarakat Kasepuhan Ciptagelar yang berjumlah $0-250$ ikat yaitu $31 \mathrm{kk}$, nilai ini lebih besar yaitu 59,61 \%. Jumlah kk yang mendapatkan padi antara 251 - 500 ikat yaitu $16 \mathrm{kk}$ dan yang mendapatkan padi per tahun antara 501 750 yaitu $5 \mathrm{kk}$.

Tabel 1 Karakteristik Sosial dan Pendapatan Padi per tahun

\section{Karakteristik sosial ekonomi Jumlah KK \\ Proporsi (\%)}

Umur :

$\begin{array}{lll}16-31 & 5 & 9,62 \\ 32-47 & 23 & 44,23 \\ 48-62 & 24 & 46,15\end{array}$

Pendidikan :

Tidak Sekolah

$\mathrm{SD}$

SMP

SMA

Besar Keluarga

$0-2$ 


\begin{tabular}{lll}
\hline Karakteristik sosial ekonomi & Jumlah KK & Proporsi (\%) \\
\hline $3-4$ & 37 & 71,15 \\
$5-6$ & 8 & 15,38 \\
Pendapatan Padi per tahun & & \\
$0-250$ ikat & 31 & 59,61 \\
$251-500$ ikat & 16 & 30,76 \\
$501-750$ ikat & 5 & 9,61 \\
\hline
\end{tabular}

Sumber: Data Olahan, 2018

Tabel 2 Jumlah dan persentase pekerjaan responden

\begin{tabular}{|c|c|c|}
\hline Variabel & Jumlah & Persentase \\
\hline Tidak bekerja & 1 & 1,92 \\
\hline Petani & 48 & 92,30 \\
\hline Nonpetani & 3 & 5,76 \\
\hline
\end{tabular}

Sumber: Data Olahan, 2018

Pekerjaan kepala rumah tangga lainnya untuk diperjualbelikan dan hanya untuk selain bertani yaitu sebesar $5,76 \%$ konsumsi rumah tangga. diantaranya berjualan sembako selain beras dan sebagai guru sekolah di wilayah Kasepuhan Ciptagelar sedangkan yang tidak bekerja hanya $1,92 \%$. (Tabel 2).

Pekerjaan selain sebagai petani b. Ketersediaan Pangan Rumah Tangga Ketersediaan pangan merupakan salah satu indikator dalam pencapaian ketahanan pangan, khususnya dalam hal penyediaan umumnya merupakan pekerjaan sampingan yang dilakukan oleh sebagian responden untuk menambah pendapatan rumah tangga. Hal ini dikarenakan adanya aturan adat bahwa hasil pertanian utama di daerah tersebut yaitu padi tidak diperbolehkan bahan pangan untuk konsumsi pangan baik pada tingkat individu, rumah tangga, ataupun masyarakat. Selanjutnya kondisi ketahanan pangan sebagai outcome dari tercukupinya ketersediaan, distribusi, dan konsumsi pangan mencerminkan tingkat kecukupan zat gizi serta kondisi kesehatan individu (Eicher et al. 2009). Jumlah lenit rata-rata 
berikut banyaknya jumlah padi di masyarakat Kasepuhan Ciptagelar dapat dilihat pada Tabel 3.

Rata-rata jumlah lumbung padi setiap rumah tangga di Kasepuhan Ciptagelar adalah 2,08 buah. Sementara itu, satu lumbung padi umumnya dapat menampung sekitar 300 - 1.000 ikat padi, atau sekitar 1500 - $3500 \mathrm{~kg}$ gabah kering (1 ikat padi rata-rata berisi 4 - $5 \mathrm{~kg}$ gabah kering). Rata-rata jumlah Tabel 3 Ketersediaan pangan rumah tangga berdasarkan leuit

\begin{tabular}{ll}
\hline \multicolumn{1}{c}{ Karakteristik Leuit } & Rata - rata per rumah tangga \\
\hline Jumlah Lenit (buah) & 2,08 \\
Jumlah padi dalam Lenit (ikat) & 400,88 \\
\hline
\end{tabular}

Sumber: Data Olahan, 2018

\section{Daya Dukung Lahan Pertanian Masyarakat Kasepuhan Ciptagelar}

Analisis daya dukung lahan dilakukan untuk memperoleh gambaran kemampuan lahan dalam memenuhi kebutuhan pangan di masyarakat Kasepuhan Ciptagelar.

Setelah diketahui nilai-nilai dari setiap komponen yang diperlukan dalam perhitungan daya dukung lahan, selanjutnya menilai daya dukung lahan dengan memasukkan nilai-nilai tersebut ke dalam rumus Odum, Christeiler, Ebenezer Howard dan Issard dalam Moniaga.

Hasil analisis pada Tabel 4 menunjukkan bahwa tingkat daya dukung lahan pertanian di Masyarakat Kasepuhan Ciptagelar adalah tersebut hampir sama dengan rata-rata jumlah lumbung padi yang dimiliki oleh masyarakat adat lainnya. Hal ini sebagaimana dikemukakan oleh Khomsan et al. (2012), bahwa rata-rata lumbung padi yang dimiliki oleh masing-masing rumah tangga Suku Baduy Luar adalah 1.2 buah yang berisi kurang lebih sekitar 457 ikat padi, rata-rata lumbung padi pada masyarakat Suku Baduy Dalam berisi sekitar 415 ikat padi. 
dukung lahan menunjukkan bahwa ketersediaan lahan pada wilayah setempat masih dapat mencukupi kebutuhan akan produksi hayati di wilayah tersebut. Keadaan surplus ini juga telah diprediksi oleh $A b a h$ Ugi (pimpinan adat Kasepuhan Ciptagelar), dalam pernyataannya:

"Pare nu aya disakabeb jero lenit eta cukup jeung beukeul nepikeun 20 tahun kahareup". (Gabah yang tersedia di Tabel 4 Nilai daya dukung lahan

\begin{tabular}{ccccc}
\hline $\begin{array}{c}\text { Luas } \\
\text { Lahan } \\
\text { panen (ha) }\end{array}$ & $\begin{array}{c}\text { Penduduk } \\
\text { Sampel }\end{array}$ & $\begin{array}{c}\text { Kebutuhan Fisik } \\
\text { Minimum } \\
\text { (kg/kapita/tahun } \\
\text { ) }\end{array}$ & $\begin{array}{c}\text { Produksi lahan } \\
\text { rata-rata per } \\
\text { hektar (kg/ha) }\end{array}$ & $\begin{array}{c}\text { Daya dukung } \\
\text { lahan } \\
\text { pertanian }\end{array}$ \\
\hline 48.115 & 186 & 124.80 & 694.07 & 1.44 \\
\hline
\end{tabular}

Sumber: Data Olahan, 2018

\section{REFERENSI}

Bernstain H. 2014. Tantangan Kedaulatan Pangan. Bandung: ARC Books

[BPS] Badan Pusat Statistik. 2012. Jawa Barat dalam Angka 2012. Bandung (ID): Badan Pusat Statistik Provinsi Jawa Barat Kerjasama dengan Bappeda Provinsi Jawa Barat.

[Depkes] Departemen Kesehatan RI. 2011.

Profil Kesehatan Indonesia 2010. Kementerian Kesehatan Republik Indonesia. Jakarta (ID): Depkes RI. selurub lumbung di sini masib cukup untuk kebutuhan sampai 20 tahun ke depan)..

Dengan demikian, kearifan budaya lokal masyarakat Kasepuhan Ciptagelar menunjukkan hasil yang baik dalam memenuhi kebutuhan berasnya.

Hasil dari perhitungan dengan rumus tersebut tertera pada Tabel 4. 
Pangan Suku Baduy. Bogor (ID): IPB

Press.

Kusnaka A. 1992. Kasepuhan yang Tumbuh di atas yang Luhur. Bandung : PT. Tarsito.

Moniaga, V. R. (2011). Analisis daya dukung lahan pertanian. Agri-Sosioekonomi, 7(2), 61-68.

Saleh I. 1999. Strategi Meningkatkan Ketahanan Pangan di Indonesia. Seminar Nasional Ketahanan Pangan, Gizi dan Keluarga, 1 mei 1999, GMKS-IPB, Bogor.

Susanto IW. 2011. Analisis Daya Dukung Lingkungan Sektor Pertanian Berbasis Produktivitas Di Kabupaten Bangli. Bumi Lestari Journal of Environment, 13(1).

Tim Wacana Nusantara. 2013. Masyarakat Adat Desa Ciptagelar. http://wacananusantara.org/kehidup an-kolektif-kebudayaanmasyarakatdesaciptagelar/.

Umar H. 2001. Riset Sumber Daya Manusia Dalam Organisasi, PT. Gramedia Pustaka Utama. Jakarta (ID) Undang-Undang Nomor 18 Tahun 2012. Tentang Pangan. Jakarta. Presiden RI. 